\title{
D376E, A205V and A122S substitutions recently found in A. palmeri confer cross-resistance to ALS-inhibiting herbicides
}

\author{
Valeria E Palmieri $^{\mathrm{b} *} \oplus$, Alvaro S Larran ${ }^{\mathrm{b}} \odot$, Andrea K Martinatto ${ }^{\mathrm{b}} \oplus$, Hugo R Permingeat ${ }^{\mathrm{a}, \mathrm{b}} \odot$, Valeria E Perotti ${ }^{\mathrm{a}} \odot$ \\ a Laboratorio de Biología Molecular, Facultad de Ciencias Agrarias, Universidad Nacional de Rosario, Campo Experimental Villarino, Zavalla, Argentina. \\ 'Instituto de Investigaciones en Ciencias Agrarias de Rosario, Facultad de Ciencias Agrarias, Universidad Nacional de Rosario, Campo Experimental \\ Villarino, Zavalla, Argentina.
}

\begin{abstract}
Background: Amaranthus palmeri S. Watson is a serious problem in soybean crops from Argentina. This weed has evolved high level of resistance to (ALS)-inhibiting herbicides mainly due to a target-site mechanism by an altered ALS enzyme. In an A. palmeri population from Totoras with cross-resistance to (ALS)-inhibiting herbicides, six allelic versions of the ALS enzyme were identified.

Objective: The aim of this study was to evaluate plants from that resistant population carrying the ALS substitutions A122S, D376E or A205V, which had not been characterized before for this species.

Methods: Subpopulations with each substitution were produced by a vegetative cloning procedure or by cross-pollination and dose-response assays and herbicide single-dose tests were performed to evaluate in vivo resistance levels to (ALS)-inhibiting herbicides.
\end{abstract}

Keywords: ALS isoforms; herbicide resistant weeds; Amaranthus palmeri; propagative cloning

Results: Dose-response experiments showed that all the resistant subpopulations survived at the highest doses tested (32X) for imidazolinones, triazolopyrimidines and sulfonylureas, while the susceptible population was completely controlled at considerably lower doses. Furthermore, an analysis of the novel A122S substitution showed that it provides cross-resistance to five classes of (ALS)-inhibiting herbicides, excluding the entire ALS herbicide group as an effective control tool in weed populations carrying this substitution.

Conclusions: The results indicated that D376E, A205V and A122S substitutions found for the first time in A. palmeri confer cross-resistance to the most used chemical families from herbicide group 2. Interestingly, it was confirmed that the A205V substitution conferred resistance to herbicides in the triazolopyrimidines family. Data generated should be considered in management strategies for delaying the spread of resistance.
Journal Information:

ISSN - 2675-9462

Website: http://awsjournal.org

Journal of the Brazilian Weed

Science Society

How to cite: Palmieri VE, Larran AS, Martinatto AK, Permingeat HR, Perotti VE. D376E, A205V and A122S substitutions recently found in $A$. palmeri confer cross-resistance to ALS-inhibiting herbicides. Adv Weed Sci. 2022;40(Spec2):e20210079. hitpsi//doiorg /10.51694/AdweedSci/2022;40:Amaranthus004

Approved by:

Editor in Chief: Anderson Luis Nunes

Associate Editor: Todd Gaines

Conflict of Interest: The authors declare that there is no conflict of interest regarding the publication of this manuscript.

Received: August 15, 2021

Approved: November 14, 2021

* Corresponding author:

<valeria.perotti@unr.edu.ar>

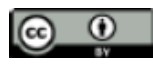

This is an open-access article distributed under the terms of the

Creative Commons Attribution License, which permits unrestricted use, distribution, and reproduction in any medium, provided that the original author and source are credited.

Copyright: 2021

\section{Introduction}

Palmer amaranth (Amaranthus palmeri S. Watson) is an extremely competitive weed given its huge stress tolerance, genetic variability, high growth rate, and reproduction capacity (Ward et al., 2013). It is a dioecious species, therefore its reproductive biology favors the dispersion and recombination of alleles, speeding up herbicide resistance evolution along withother traits. For instance, the transfer of glyphosate resistance from resistant males to susceptible female plants by pollen has been demonstrated up to a distance of $300 \mathrm{~m}$ (Culpepper et al., 2006). In addition, A. palmeri can hybridize with other species of the genus (Franssen et al., 2001; Gaines et al., 2012; Trucco et al., 2007). This property also increases the probability of finding populations with multiple herbicide resistance.

In most cases, resistance to (ALS)-inhibiting herbicides in Amaranthus spp. is caused by changes in the sequence of the ALS gene (Ashigh et al., 2009; Larran et al., 2018; McNaughton et al., 2005; Molin et al., 2016; Nakka et al., 2017; Singh et al., 2019; Trucco et al., 2006). However, although many of these substitutions reduce ALS enzyme sensitivity in vitro (Yu, Powles, 2014), not all of them provide robust protection against herbicide damage. For instance, the level of in vitro resistance to thifensulfuron for ALS with S653N substitution from Amaranthus tuberculatus was 4-fold higher than the wild type enzyme, but this substitution was not enough to confer resistance to ALS inhibitors herbicides in vivo (Patzoldt, Tranel, 2007).

Weed populations are infrequently composed of only resistant or only susceptible individuals to a specific herbicide (Cousens, Mortimer, 1995). In cross-pollinated weeds, and even in self-pollinated species, a great diversity of ALS mutations is often found. Thus, to confirm the level of resistance for a specific ALS mutation, plants carrying exclusively a specific substitution must be selected or generated, and then tested.

The generation of purified subpopulations (from homozygous individuals) is one of the most widespread methodologies to study herbicide resistance in weeds (Deng et al., 2017; Yu et al., 2012). However, this practice is hard for cross-pollinated weeds species 
with different ALS substitutions, such A. palmeri. For that reason, Teaster and Hoagland (2014) developed a macrovegetative propagation method that facilitates long-term studies in selected cloned lines of $A$. palmeri.

Over the past few years, we found a target-site resistance due to specific $A L S$ mutations in an A. palmeri population from Totoras (Santa Fe, Argentina) (Larran et al., 2017). In this work, we selected, cloned and evaluated plants from that resistant population of A. palmeri carrying the ALS substitutions A122S (Larran et al., 2017), or D376E and A205V, which had not been characterized before for this species. Even more, this is the first characterization of the novel A122S substitution in plants. The resistance profile to different (ALS)-inhibiting herbicides was elucidated. Data generated can be useful to make the right weed management recommendations for delaying the spread of resistance.

\section{Materials and Methods}

\subsection{Plant material}

The original A. palmeri population ( $\mathrm{R}$ ) was collected from a field in Totoras ( $32^{\circ} 34^{\prime} 59.88^{\prime \prime}$, 61 $61^{\circ} 10^{\prime} 59.88^{\prime \prime} \mathrm{W}$ ) in which DERBY $^{\circledR}$ (a.i. imazethapyr $10 \% \mathrm{w} / \mathrm{v}$; Gleba, La Plata, Argentina) had been continuously used for at least ten years. The susceptible population (S) was collected in a field from Tucumán ( $\left.27^{\circ} 17^{\prime} 45.36^{\prime \prime} \mathrm{S}, 65^{\circ} 0^{\prime} 3.37^{\prime \prime} \mathrm{W}\right)$, where (ALS)-inhibiting herbicides had never been used.

\subsection{Plant selection with the D376E, A205V or A122S ALS substitutions}

Plants from the resistant population were selected by application of DERBY at dose $1 \mathrm{X}\left(100 \mathrm{~g}_{\text {ai ha }}{ }^{-1}\right)$ as described in Larran et al. (2017). Surviving plants were sampled for $A L S$ gene sequencing and/or marker analysis to define the resistance mutation of each individual.

The complete $A L S$ gene of each plant was amplified and cloned in pGEM $^{\circledR}$-T easy vector (Life Technologies, Grand Island, NY, USA) as described in Larran et al. (2017). Then, these recombinant DNA molecules were sequenced (Macrogen Inc., Seoul, Korea).

Derived cleaved amplified polymorphic sequence (dCAPS) markers were developed for the identification of A122S substitution by screening 50 surviving plants. The primers used were ALSdcaps122f (5'-CTAAACCTCC TTCCGCTACTATAACTCAATCACC-3') and ALSdcaps122r (5'-CGAGTAAGAGCTTGATGGATTTCCATGCATG-3'). The amplification reactions were performed in a final volume of $12 \mu \mathrm{l}$, containing: $0.2 \mathrm{mM}$ dNTPs mix, $0.5 \mu \mathrm{M}$ primers, $1 \mathrm{X}$ amplification buffer and $0.48 \mathrm{U}$ of the GoTaq ${ }^{\circledR}$ DNA Polymerase enzyme (Promega). The PCR program was $95^{\circ} \mathrm{C}$ for $2 \mathrm{~min} ; 35 \mathrm{cycles}$ of $95^{\circ} \mathrm{C}$ for $30 \mathrm{~s}, 58^{\circ} \mathrm{C}$ for $30 \mathrm{~s}, 72^{\circ} \mathrm{C}$ for $30 \mathrm{~s}$ and a final step at $72^{\circ} \mathrm{C}$ for $5 \mathrm{~min}$. Restriction digestions were carried out with SphI enzyme (Biolabs New England) which recognizes and cuts the sequence $G C A T G^{\wedge} C$ present in WT sequence. The WT sequence produces a 171-bp digested band, whereas sequence with A122S substitution produces a 202-bp undigested band. DNA bands were visualized on $6 \% \mathrm{w} / \mathrm{v}$ polyacrylamide gels stained with SYBR safe (Invitrogen ${ }^{\circledR}$ ).

\subsection{Vegetative cloning of plants carrying the D376E, A205V or A122S ALS substitutions}

A vegetative cloning procedure was used to achieve homogeneous material (three subpopulations). Each selected plant was multiplied using the protocol described by Teaster and Hoagland (2014), which, briefly, is based on isolating cuttings, coating the cut end with rooting hormone powder, planting them in moistened vermiculite/ peat/loam mixture and incubating them under continuous light $\left(150 \mu \mathrm{mol} \mathrm{m} \mathrm{m}^{-2} \mathrm{~s}^{-1}\right)$ for 7 days. Clone cultivation was carried out under normal growth conditions $\left(25^{\circ} \mathrm{C}\right.$, photoperiod 16:8 hours day/night, light intensity of $400 \mu \mathrm{mol} \mathrm{m}^{-2} \mathrm{~s}^{-1}$ ).

\subsection{Chemical compounds}

Five herbicides were used in different assays: DERBY ${ }^{\circledR}$ (a.i. imazethapyr $10 \% \mathrm{w} / \mathrm{v}$; Gleba, imidazolinones), VRILEC $^{\circledR}$ (a.i. chlorimuron-ethyl 25\% w/w; Agrofina, sulfonylureas), SPIDER ${ }^{\circledR}$ (a.i. diclosulam $84 \%$ w/w; Dow Agro-Sciences, triazolopyrimidines), EVEREST 70WDG ${ }^{\circledR}$ (a.i. flucarbazone sodium $70 \% \mathrm{w} / \mathrm{w}$, Arysta LifeScience, sulfonylaminocarbonyltriazolinone) and NOMINEE GOLD $^{\circledR}$ (bispyribac sodium $40 \% \mathrm{w} / \mathrm{v}$, SummitAgro, pyrimidinylthiobenzoates).

\subsection{Dose-response assays}

At least 120 vegetative clones from each subpopulation R1 (D376E), R2 (A205V) and R3 (A122S) and plants from population $S$ were grown in $500 \mathrm{~cm}^{3}$ pots as described in Larran et al. (2017). Commercial herbicide formulations were applied when plants reached $8-10 \mathrm{~cm}$ height at the following doses: imazethapyr (50, 100, 200, 400, 800, 1,600 and $3,200 \mathrm{~g}$ ai ha $\left.^{-1}\right)$, chlorimuron-ethyl $(25,50,100$, 200, 400, 800 and 1,600 $\left.\mathrm{g}_{\text {ai ha }}{ }^{-1}\right)$ and diclosulam (15, 30, $60,120,240,480$ and $\left.960 \mathrm{~g}_{\text {ai ha }}{ }^{-1}\right)$. The dose-response curves were analyzed as described in Larran et al. (2017). The experiment was conducted using six replicates per dose.

\subsection{Herbicide single-dose test on the R3.2 population}

A population of $A$. palmeri (here in after referred as R3.2) carrying the A122S substitution in homozygosis was generated by crossing two homozygous plants (a female and a male) for such substitution. Seeds were harvested and stored until use. 
To remove physiological dormancy, seeds from both R3.2 and $S$ populations were imbibed for 7 days on agar solution $(0.1 \% \mathrm{w} / \mathrm{v})$ at $4^{\circ} \mathrm{C}$. After that, plants were grown and separately sprayed at recommended field doses (1X) of the next herbicides: imazethapyr (100 $\mathrm{g}$ ai ha $\mathrm{a}^{-1}$ ), chlorimuron-ethyl (50 $\mathrm{g}$ ai ha $\mathrm{h}^{-1}$ ), diclosulam (30 $\mathrm{g}$ ai ha ${ }^{-1}$ ), flucarbazone sodium (150 $\mathrm{g}$ ai ha ${ }^{-1}$ ) and bispyribac sodium $\left(40 \mathrm{ml} \mathrm{ha}^{-1}\right)$. Ten replicated pots from each R3.2 and S populations, for each herbicide were used. Twenty one days after treatment (DAT), the number of surviving plants and their fresh biomass were recorded. Data were analyzed by t-Student tests using SigmaPlot software (version 11.0; Systat Software, Inc).

\section{Results and Discussion}

\subsection{Herbicide resistance in R1, R2 and R3 subpopulations}

In vivo resistance levels to (ALS)-inhibiting herbicides were evaluated in vegetative clones carrying the D376E, A205V or A122S ALS substitutions (R1, R2 and R3 subpopulations, respectively). These subpopulations were produced by a vegetative cloning procedure to develop homogeneous material (Figure 1). Plants selected for cloning were screened from a resistant population of $A$. palmeri (Larran et al., 2017) by ALS sequencing (D376E, A205V) or by dCAPS (A122S) (Figure 2), according to each genotype frequency.

Dose-response experiments showed that all the $R$ subpopulations survived at the highest doses tested (32X) for each herbicide, while the S population was completely controlled at considerably lower doses (Figure $3 \mathrm{a}-\mathrm{c}$ ). However, $\mathrm{S}$ population seems to be slightly less sensitive to chlorimuron-ethyl, since the $\mathrm{LD}_{50}$

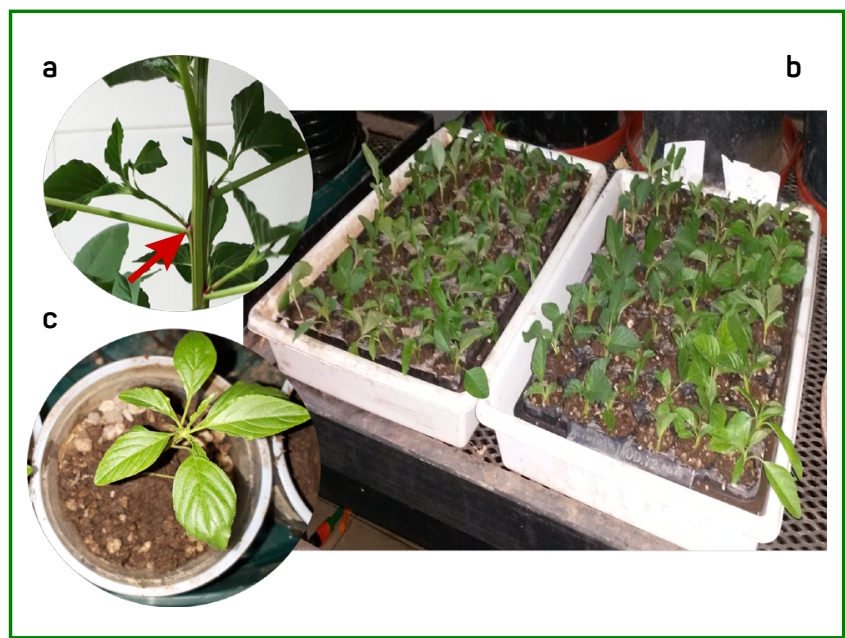

Cuttings for cloning (5 $\mathrm{cm}$ in length) (a). Shoots, after 15 days, with established roots (b). Clone utilized for dose-response curves $(8-10 \mathrm{~cm}$ in length) (c).

Figure 1 - Vegetative cloning procedure of plants of A. polmeri carrying the D376E, A205V or A122S ALS substitutions
(73 $\mathrm{g}$ ai ha $\mathrm{a}^{-1}$ ) is higher than the recommended field dose (50 $\mathrm{g}$ ai ha ${ }^{-1}$ ). Therefore, this population might carry a non-target site resistance to ALS inhibitors, since it has wild-type ALS (data not shown) and is not fully sensitive to chlorimuron-ethyl $\left(\mathrm{GR}_{50}\right.$ is $86 \mathrm{~g}$ ai ha-1), if other susceptible populations of $A$. palmeri are considered (Burgos et al., 2001; Nakka et al., 2017).

Although the $\mathrm{R}$ subpopulations survived at all herbicides doses, the growth rate was decreased, affecting the biomass after each treatment (Figure 3 d-f). Resistant Factors (Rf) estimated from $\mathrm{GR}_{50}$ ranged from 10-21 to 19-83 for imazethapyr and diclosulam, respectively (Table 1 ). Regarding chlorimuron-ethyl, only R2 subpopulation showed a significant but low Rf (1.6). This may be caused by the $S$ population not being completely susceptible to chlorimuron-ethyl, leading to an under-estimation of genuine resistance levels to this chemical family.

In summary, these results indicate that these substitutions found for the first time in A. palmeri confer cross-resistance to the most used chemical families from herbicide group 2 [imidazolinones (IMI), triazolopyrimidines (TP) and sulfonylureas (SU)].

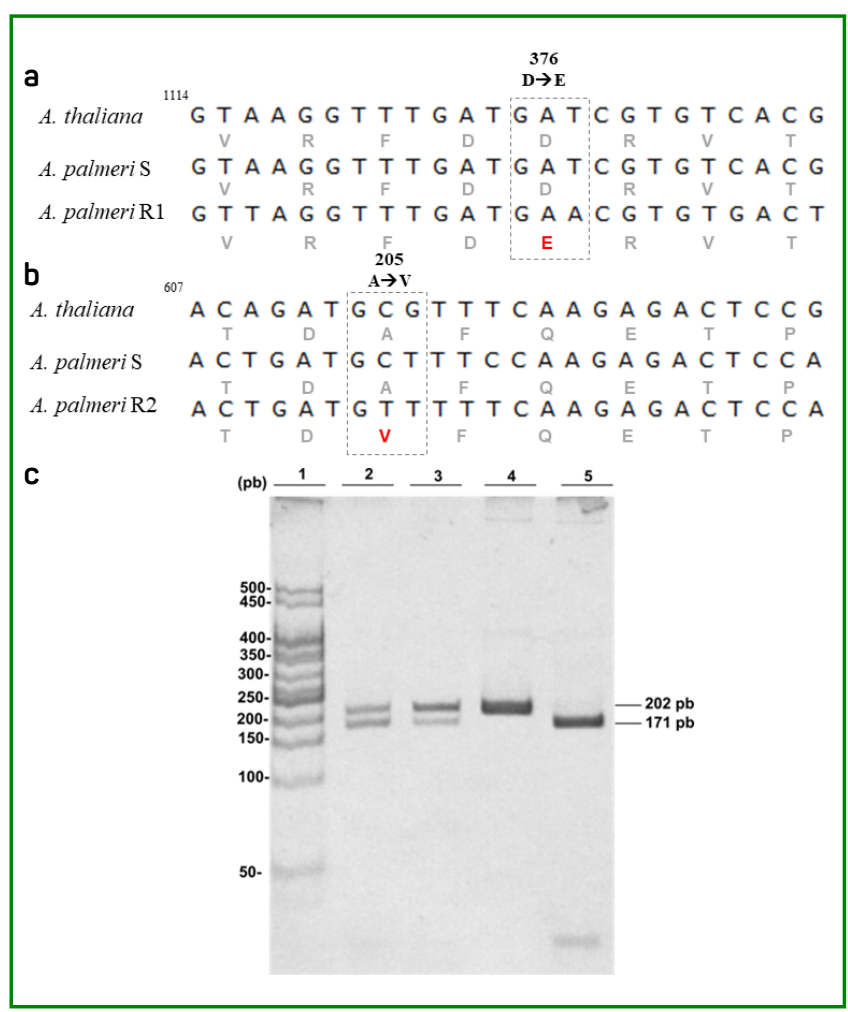

Amino acids are numbered according to A. thaliana ALS sequence (AAK68759). The DNA bands were visualized on $6 \% \mathrm{w} / \mathrm{v}$ polyacrylamide gels stained with SYBR safe. The WT sequences produced a 171-bp digested band (lanes 2, 3 and 5), and sequences with A122S mutation produced a 202-bp undigested band (lanes 2, 3 and 4).

Figure 2 - Scheme of ALS sequences of A. palmeri from R1 (a) and R2 (b) subpopulations and dCAPS analysis for screening the A122S substitution to produce R3 subpopulation (c) 
a

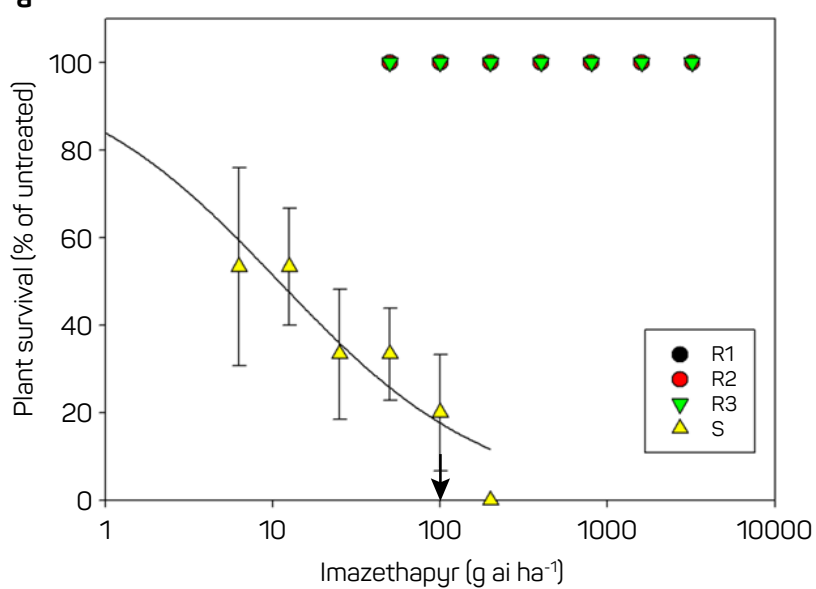

b

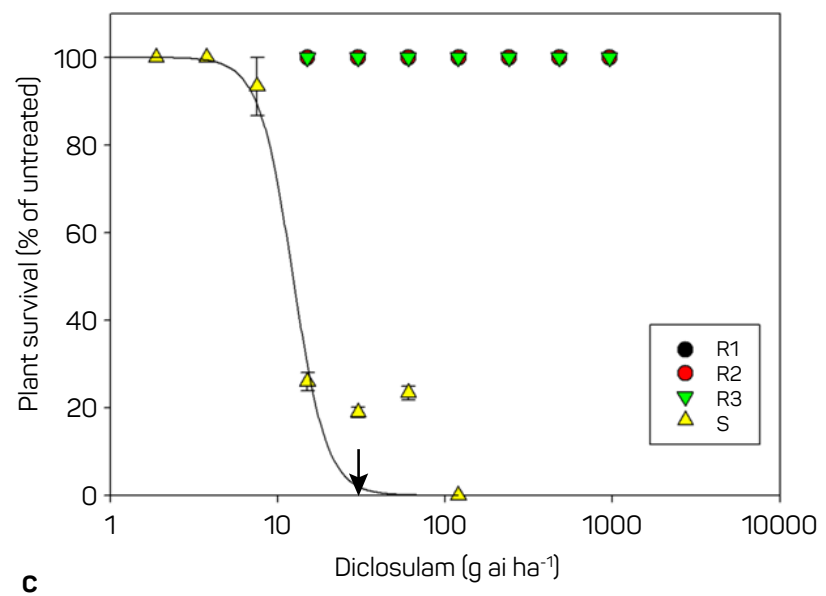

C

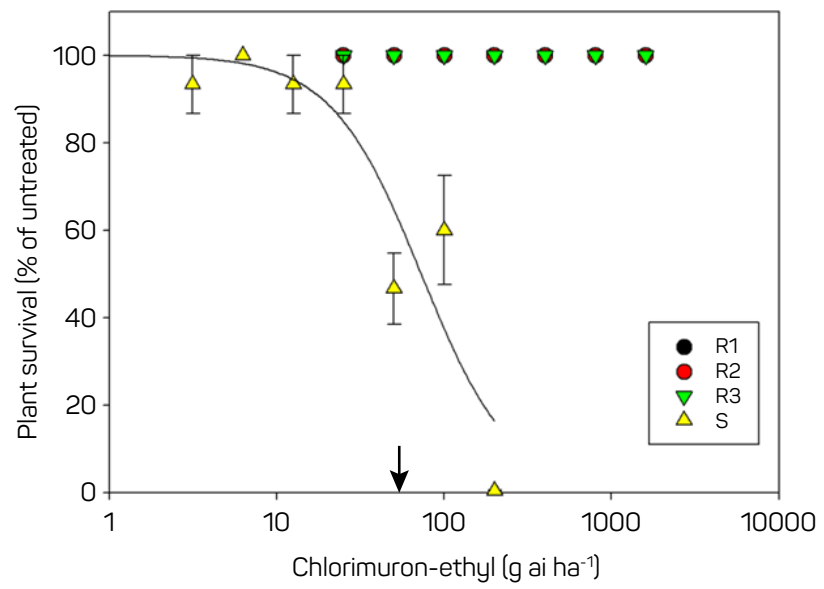

d

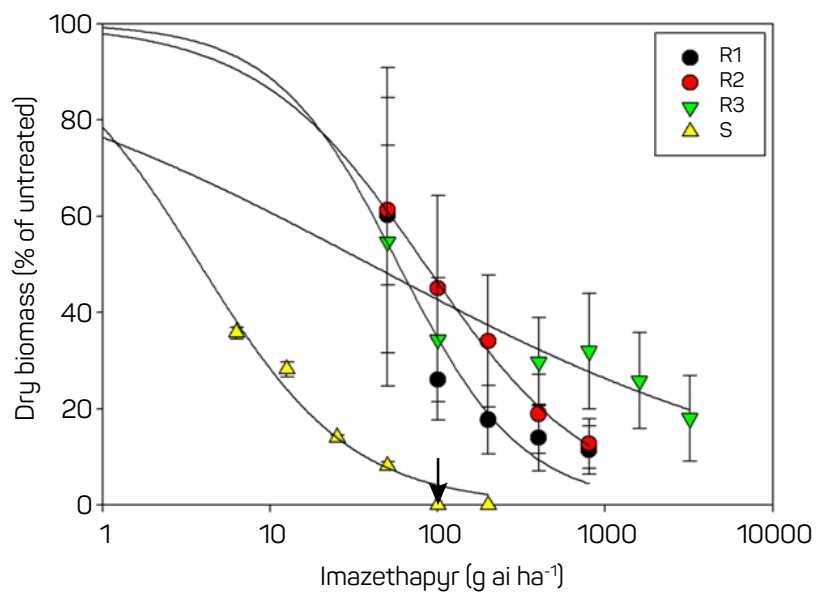

e

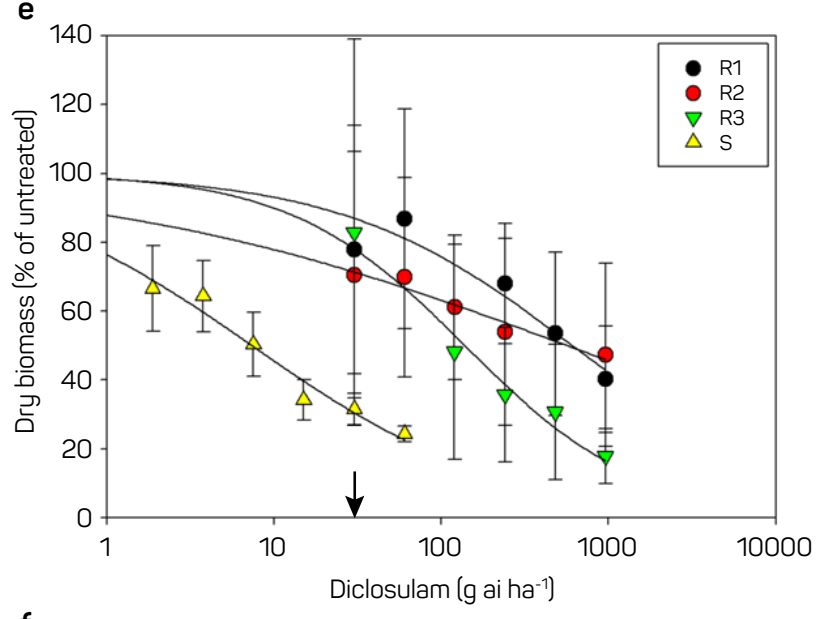

$\mathbf{f}$

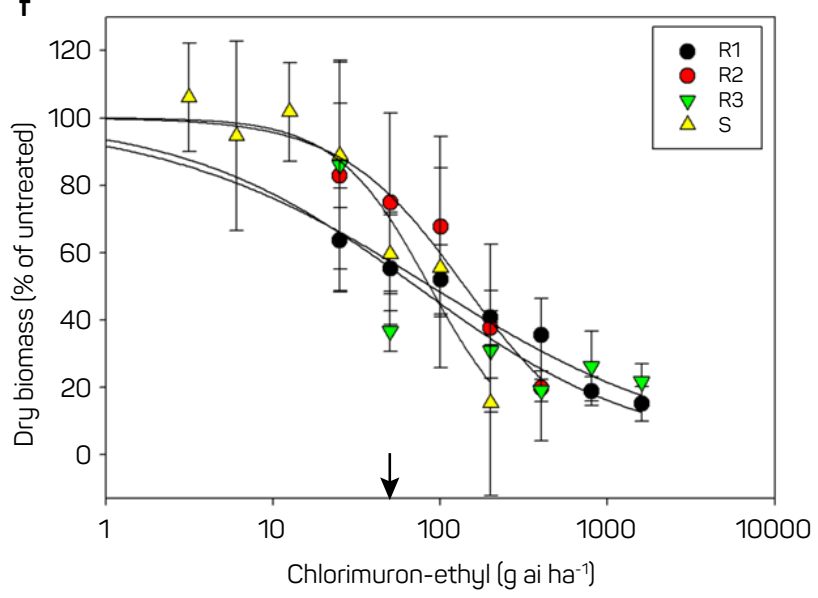

Results are expressed as a percentage of plant survival (a-c) and dry biomass (d-f) in comparison to untreated control groups. Arrows indicate the recommended field doses. Vertical bars represent standard error.

Figure 3 - Dose-response curves with ALS-inhibiting herbicides in vegetative clones of A. polmeri (R1, R2 and R3 subpopulations)

The cross-resistance conferred by the D376E substitution is consistent to previous reports from other weed species (Ashigh et al., 2009; Whaley et al., 2007; Yu et al., 2012). Concerning the A205V substitution, this had been proved to provide in vivo resistance to IMI and SU families in A palmeri, as well as in other weeds (Ashigh, Tardif, 2007; Matzrafi et al., 2015; McNaughton et al., 2005). In this work, we show that A205V also confers 
Table 1 - Dose-response curve parameters of A. polmeri

\begin{tabular}{|c|c|c|c|c|c|}
\hline \multirow{2}{*}{$\begin{array}{l}\text { Herbicide } \\
\text { (family) }\end{array}$} & \multirow{2}{*}{$\begin{array}{l}\text { Vegetal } \\
\text { material }\end{array}$} & \multicolumn{4}{|c|}{ Parameters } \\
\hline & & $\mathrm{LD}_{50}$ & Rf & $\mathrm{GR}_{50}$ & Rf \\
\hline \multirow{4}{*}{$\begin{array}{l}\text { Imazethapyr } \\
\text { (IMI) }\end{array}$} & $\mathrm{R} 1$ & >3200 & $>290$ & $58 \pm 10^{*}$ & 15.3 \\
\hline & $\mathrm{R} 2$ & >3200 & $>290$ & $83 \pm 3^{*}$ & 21.8 \\
\hline & R3 & >3200 & $>290$ & $39 \pm 12^{*}$ & 10.3 \\
\hline & $S$ & $11 \pm 3$ & - & $3.8 \pm 0.6$ & - \\
\hline \multirow{4}{*}{$\begin{array}{l}\text { Diclosulam } \\
\text { (TP) }\end{array}$} & $\mathrm{R} 1$ & $>960$ & $>80$ & $607 \pm 142^{*}$ & 83.1 \\
\hline & $\mathrm{R} 2$ & $>960$ & $>80$ & $564 \pm 114 *$ & 77.3 \\
\hline & R3 & $>960$ & $>80$ & $137 \pm 17^{*}$ & 18.8 \\
\hline & $S$ & $12 \pm 2$ & - & $7.3 \pm 0.8$ & - \\
\hline \multirow{4}{*}{$\begin{array}{l}\text { Chlorimuron-ethyl } \\
\text { (SU) }\end{array}$} & $\mathrm{R} 1$ & $>1600$ & $>22$ & $89 \pm 19$ & 1 \\
\hline & $\mathrm{R} 2$ & $>1600$ & $>22$ & $140 \pm 14^{*}$ & 1.6 \\
\hline & R3 & $>1600$ & >22 & $71 \pm 36$ & 0.8 \\
\hline & $S$ & $73 \pm 17$ & - & $86 \pm 11$ & - \\
\hline
\end{tabular}

Resistance factors (Rfs) were calculated using $\mathrm{LD}_{50}$ or $\mathrm{GR}_{50}$ of $\mathrm{R}$ subpopulations and $S$ population. * indicate statistically significant differences between $\mathrm{R}$ subpopulations and S population (t-Student, $\mathrm{p}<0.05$ ).

resistance to TP, a chemical family not evaluated before for this mutation.

Finally, the novel A122S substitution showed crossresistance to the three chemical families evaluated, similarly to other mutations at the same position, such as A122Y and A122N, reported in Raphanus raphanistrum and Echinochloa crus-galli, respectively (Han et al., 2012; Panozzo et al., 2017).

\subsection{Deeping on the in vivo characterization of the novel A122S ALS substitution}

The macro-vegetative propagation technique allows obtaining numerous clones that can be used as replicates in resistance tests. It has been used to study resistance to multiple herbicides in different Amaranthus species, as well as to characterize the response of $A$. palmeri to abiotic stress (Korres et al., 2017; Ma et al., 2013; Shergill et al., 2018; Teaster, Hoagland, 2014).

Herbicide single-dose tests were performed using plants from seeds of the R3.2 population obtained to discard any artifact of the technique on the resistance phenotype observed in the clones. Also, two additional herbicides from other families (flucarbazone sodium and bispyribac sodium) were included to assess them as possible control tools for this population.

Treatments with imazethapyr, diclosulam and flucarbazone sodium at $1 \mathrm{X}$ doses failed to control the R3.2 population while plant survival in $S$ population decreased (100\% vs $50-60 \%$ ) (Table 2). On the other hand, chlorimuron-ethyl and bispyribac sodium applications did not control individuals from the R3.2 population, suggesting resistance; however, these doses did not control
Table 2 - Plant survival and fresh biomass 21 DAT of $A$. polmeri S and R3.2 populations

\begin{tabular}{|c|c|c|c|c|}
\hline \multirow{2}{*}{ Treatment } & \multicolumn{2}{|c|}{$\begin{array}{c}\text { Plant survival } \\
\text { (\% of untreated) }\end{array}$} & \multicolumn{2}{|c|}{$\begin{array}{l}\text { Fresh biomass } \\
\text { (g) }\end{array}$} \\
\hline & s & R3.2 & s & R3.2 \\
\hline Untreated & & & $1.0 \pm 0.2$ & $1.2 \pm 0.3$ \\
\hline Imazethapyr & $50 \pm 16$ & $100^{*}$ & $0.22 \pm 0.08^{*}$ & $0.7 \pm 0.1$ \\
\hline Chlorimuron-ethyl & $70 \pm 15$ & $75 \pm 18$ & $0.5 \pm 0.2$ & $0.5 \pm 0.1^{*}$ \\
\hline Diclosulam & $60 \pm 16$ & $100^{*}$ & $0.4 \pm 0.1^{*}$ & $0.87 \pm 0.08$ \\
\hline $\begin{array}{l}\text { Flucarbazone } \\
\text { sodium }\end{array}$ & $60 \pm 16$ & $100^{*}$ & $0.3 \pm 0.1^{*}$ & $0.6 \pm 0.1$ \\
\hline $\begin{array}{l}\text { Bispyribac } \\
\text { sodium }\end{array}$ & $90 \pm 10$ & 100 & $0.52 \pm 0.09^{*}$ & $0.65 \pm 0.04$ \\
\hline
\end{tabular}

* indicate statistically significant differences as compared to $S$ population (plant survival) and to untreated samples (fresh biomass) (t-Student, $\mathrm{p}<0.05)$.

the $S$ population. Once more, the lower susceptibility to chlorimuron-ethyl in the $S$ population could explain part of these results. Curiously, if considering treated vs untreated plants from the R3.2 population, only chlorimuron-ethyl showed significant effects on biomass (Table 2). Regarding bispyribac sodium, it is possible that the appropriate $1 \mathrm{X}$ dose for $\mathrm{A}$. palmeri should be higher than the $1 \mathrm{X}$ dose indicated for other weed species, given that experiments with a $4 \mathrm{X}$ dose allowed a differential survival rate between R3.2 (100\%) and S population (60\%) (data not shown).

Thus, we confirmed that macro-vegetative propagation is a reliable tool to evaluate herbicide resistance in $A$. palmeri, since the results from in vivo tests with plants obtained from seeds are consistent with those observed using clones. In addition, we proved that the novel substitution $\mathrm{A} 122 \mathrm{~S}$ endows cross-resistance to five classes of (ALS)-inhibiting herbicides, excluding this herbicide group as an effective control tool in weed populations carrying this substitution.

\section{Conclusions}

In vivo resistance to (ALS)-inhibiting herbicides was confirmed in A. palmeri plants carrying the ALS substitutions D376E, A205V or A122S, which had not been characterized before for this species. These three amino acid substitutions confer cross-resistance to SU, IMI and TP, the most used chemical families from herbicide group 2. Additionally, a deeper analysis of the A122S substitution supported two main conclusions: i) this novel substitution endows cross-resistance to five classes of (ALS)-inhibiting herbicides; and ii) the macro-vegetative propagation is a reliable tool to evaluate herbicide resistance in A. palmeri. 
Data generated should be considered to support weed management recommendations.

\section{Authors' contributions}

VEP and VEP: conducted the molecular experiments, formal analysis and original draft writing. VEP: guided the research. ASL and AKM: provided assistance in different experiments, writing, and language editing. HRP: headed the funding acquisition, provided continuous supervision, and corrected the manuscript. All authors read and approved the manuscript.

\section{Acknowledgements}

We appreciate Daniel Tuesca's and Nicolás Montico's collaborations during the dose-response assays.

\section{Funding}

This work was supported by grants D-TEC0001/13 from ANPCyT/MINCyT and Resolution 119/2015-Project 2010-149-14 from SECTEI- Santa Fe Province. VEP, AKM, and ASL are fellows of IICAR-CONICET, VEP and HRP are Professors of the Universidad Nacional de Rosario (UNR) and HRP is researcher of IICAR-CONICET.

\section{References}

Ashigh J, Corbett CAL, Smith PJ, Laplante J, Tardif FJ. Characterization and diagnostic tests of resistance to acetohydroxyacid synthase inhibitors due to an Asp $_{376}$ Glu substitution in Amaranthus powellii. Pestic Bichem Physiol. 2009;95(1):38-46. Available from: https://doi. org/10.1016/j.pestbp.2009.06.002

Ashigh J, Tardif FJ. An $\mathrm{Ala}_{205}$ Val substitution in acetohydroxyacid synthase of Eastern black nightshade (Solonum ptychanthum) reduces sensitivity to herbicides and feedback inhibition. Weed Sci. 2007;55(6):558-65. Available from: https://doi.org/10.1614/ WS-07-054.1

Burgos NR, Kuk Yl, Talbert RE. Amaranthus polmeri resistance and differential tolerance of Amaranthus polmeri and Amaranthus hybridus to ALS-inhibitor herbicides. Pest Manag Sci. 2001;57(5):449-57. Available from: https://doi.org/10.1002/ps.308

Cousens R, Mortimer AM. Dynamics of weed populations. Cambridge: Cambridge University; 1995.

Culpepper AS, Grey TL, Vencill WK, Kichler JM, Webster TM, Brown $\mathrm{SM}$ et al. Glyphosate resistant Palmer amaranth (Amoronthus polmeri) confirmed in Georgia. Weed Sci. 2006;54(4):620-6. Available from: https://doi.org/10.1614/WS-06-001R.1

Deng W, Yang Q, Zhang Y, Jiao H, Mei Y, Li X et al. Cross-resistance patterns to acetolactate synthase (ALS)-inhibiting herbicides of flixweed (Descurainia sophia L.) conferred by different combinations of ALS isozymes with a Pro-197-Thr mutation or a novel Trp-574-Leu mutation. Pestic Biochem Phys. 2017;136:41-5. Available from: https://doi. org/10.1016/j.pestbp.2016.08.006

Franssen AS, Skinner DZ, Al-Khatib K, Horak MJ, Kulakow PA. Interspecific hybridization and gene flow of ALS resistance in Amoranthus species. Weed Sci. 2001;49(5):598-606. Available from: https://doi.org/10.1614/0043-1745(2001)049[0598:IHAGFO]2.0.CO;2

Gaines TA, Ward SM, Bukun B, Preston C, Leach JE, Westra P. Interspecific hybridization transfers a previously unknown glyphosate resistance mechanism in Amoronthus species. Evol Appl. 2012;5(1):29-38. Available from: https://doi.org/10.1111/j.1752-4571.2011.00204.x

Han H, Yu Q, Purba E, Li M, Walsh M, Friesen S et al. A novel amino acid substitution Ala-122-Tyr in ALS confers high-level and broad resistance across ALS-inhibiting herbicides. Pest Manag Sci. 2012;68(8):1164-70. Available from: https://doi.org/10.1002/ps.3278

Korres NE, Norsworthy JK, FitzSimons T, Roberts TL, Oosterhuis DM. Differential response of Palmer amaranth (Amaronthus palmeri) gender to abiotic stress. Weed Sci. 2017;65(2):213-27. Available from: https://doi.org/10.1017/wsc.2016.34

Larran A, Palmieri V, Perotti V, Lieber L, Tuesca D, Permingeat HR. Target-site resistance to ALS-inhibiting herbicides in Amaronthus polmeri from Argentina. Pest Manag Sci. 2017;73(12):2578-84. Available from: https://doi.org/10.1002/ps.4662

Larran AS, Lorenzetti F, Tuesca D, Perotti VE, Permingeat HR. Molecular mechanisms endowing cross resistance to ALS-inhibiting herbicides in Amoronthus hybridus from Argentina. Plant Mol Biol Report. 2018;36:907-12. Available from: https://doi.org/10.1007/s11105018-1122-y

Ma R, Kaundun SS, Tranel PJ, Riggins CW, McGinness DL, Hager $A G$ et al. Distinct detoxification mechanisms confer resistance to mesotrione and atrazine in a population of waterhemp. Plant Physiol. 2013;163(1):363-77. Available from: https://doi. org/10.1104/pp.113.223156

Matzrafi M, Lazar TW, Sibony M, Rubin B. Conyzo species: distribution and evolution of multiple target-site herbicide resistances. Planta. 2015;242(1):259-67. Available from: https://doi.org/10.1007/s00425015-2306-4

McNaughton KE, Letarte J, Lee EA, Tardif FJ. Mutations in ALS confers herbicide resistance in redroot pigweed (Amoronthus retroflexus) and Powell amaranth (Amaranthus powellii). Weed Sci. 2005;53(1):17-22. Available from: https://doi.org/10.1614/WS-04-109

Molin WT, Nandula VK, Wright AA, Bond JA. Transfer and expression of ALS inhibitor resistance from Palmer Amaranth (Amoronthus palmeri) to an A. spinosus $\times$ A. polmeri hybrid. Weed Sci. 2016;64(2):240-7. Available from: https://doi.org/10.1614/WS-D-15-00172.1

Nakka S, Thompson CR, Peterson DE, Jugulam M. Target site-based and non-target site based resistance to ALS inhibitors in Palmer amaranth (Amaranthus palmeri). Weed Sci. 2017;65(6):681-9. Available from: https://doi.org/10.1017/wsc.2017.43 
Panozzo S, Scarabel L, Rosan V, Sattin M. A new Ala-122-Asn amino acid change confers decreased fitness to ALS-resistant Echinochloo crus-galli. Front Plant Sci. 2017;8:1-13. Available from: https://doi. org/10.3389/fpls.2017.02042

Patzoldt WL, Tranel PJ. Multiple ALS mutations confer herbicide resistance in waterhemp (Amaranthus tuberculatus). Weed Sci. 2007;55(5):421-8. Available from: https://doi.org/10.1614/WS-06-213.1

Shergill LS, Barlow BR, Bish MD, Bradley KW. Investigations of 2, 4-D and multiple herbicide resistance in a Missouri Waterhemp (Amoranthus tuberculatus) population. Weed Sci. 2018;66(3):386-94. Available from: https://doi.org/10.1017/wsc.2017.82

Singh S, Singh V, Salas-Perez RA, Bagavathiannan MV, Lawton-Rauh A, Roma-Burgos N. Target-site mutation accumulation among ALS inhibitor-resistant Palmer amaranth. Pest Manag Sci. 2019;75(4):1131-9. Available from: https://doi.org/10.1002/ps.5232

Teaster ND, Hoagland RE. Characterization of glyphosate resistance in cloned Amaronthus polmeri plants. Weed Biol Manag. 2014;14(1):1-10. Available from: https://doi.org/10.1111/wbm.12024

Trucco F, Hager AG, Tranel PJ. Acetolactate synthase mutation conferring imidazolinone-specific herbicide resistance in Amoranthus hybridus. J Plant Phys. 2006;163(4):475-9. Available from: https://doi. org/10.1016/j.jplph.2005.06.015

Trucco F, Zheng D, Woodyard AJ, Walter JR, Tatum TC, Rayburn AL et al. Nonhybrid progeny from crosses of dioecious amaranths: implications for gene-flow research. Weed Sci. 2007;55(2):119-22. Available from: https://doi.org/10.1614/WS-06-132.1

Ward SM, Webster TM, Steckel LE. Palmer amaranth (Amoronthus polmeri): a review. Weed Technol. 2013;27(1):12-27. Available from: https://doi.org/10.1614/WT-D-12-00113.1

Whaley CM, Wilson HP, Westwood JH. A new mutation in plant ALS confers resistance to five classes of ALS-inhibiting herbicides. Weed Sci. 2007;55(2):83-90. Available from: https://doi.org/10.1614/WS-06-082.1

Yu Q, Han H, Li M, Purba E, Walsh MJ, Powles SB. Resistance evaluation for herbicide resistance-endowing acetolactate synthase (ALS) gene mutations using Rophonus rophonistrum populations homozygous for specific ALS mutations. Weed Res. 2012;52(2):178-86. Available from: https://doi.org/10.1111/j.1365-3180.2012.00902.x

Yu Q, Powles SB. Resistance to AHAS inhibitor herbicides: current understanding. Pest Manag Sci. 2014;70(9):1340-50. Available from: https://doi.org/10.1002/ps.3710 